Article

\title{
Analyzing the Relationship between Consumer Satisfaction and Fresh E-Commerce Logistics Service Using Text Mining Techniques
}

\author{
Wei Hong $1,2,3, *$, Changyuan Zheng ${ }^{2}$, Linhai Wu ${ }^{1,2,3}$ and Xujin Pu ${ }^{1,2,3}$ \\ 1 Food Safety Research Base of Jiangsu Province, Jiangnan University, Wuxi 214122, China \\ 2 School of Business, Jiangnan University, Wuxi 214122, China \\ 3 Institute for Food Safety Risk Management, Jiangnan University, Wuxi 214122, China \\ * Correspondence: hongwei@jiangnan.edu.cn
}

Received: 31 May 2019; Accepted: 26 June 2019; Published: 28 June 2019

\begin{abstract}
The rapid development of the Internet and the transformation of consumption patterns have prompted consumers to purchase fresh products online. For fresh e-commerce enterprises, logistics is an important aspect of customer satisfaction. Therefore, this study focused on online review information and used a convolutional neural network text mining model for its analysis. Logistics service elements concerned with customer satisfaction are convenience, communication, integrity, responsiveness, and reliability. Thereafter, comment information was converted to digital information using sentiment analysis. Finally, a correlation analysis was carried out to compare the significance of various influencing factors. The results confirm that convenience, communication, reliability, and responsiveness had a significant impact on customer satisfaction, whereas integrity had none. Fresh e-commerce logistic services need to improve for the development of the companies.
\end{abstract}

Keywords: fresh e-commerce; logistics service; customer satisfaction; convolutional neural network; sentiment analysis

\section{Introduction}

Fast-paced work and lifestyle have denied consumers the luxury of time to visit supermarkets to buy fresh foods necessary for daily life. An increasing number of consumers have embraced the idea of buying fresh food (vegetables, fruits, flowers, meat, eggs, milk, aquatic products, etc.) through the Internet to improve their quality of life. Fresh e-commerce is rapidly developing under the policy background of "Internet+". According to the "Analysis Report on the Scale and Development Prospect of China's Fresh E-commerce Market in 2018-2023" released by the China Industrial Research Institute, in recent years, China's fresh e-commerce has achieved rapid development. In 2017, the transaction volume of the fresh market reached 1789.7 billion yuan, and the transaction volume of the fresh e-commerce market was 141.8 billion yuan. The penetration rate of the online market continued to increase, reaching $7.9 \%$. However, fresh e-commerce remains at a disadvantage in competition with the traditional way of selling agricultural products due to issues regarding retaining the freshness of food, logistics, and other factors. Thus, the supply chain, logistics system, and other elements must be further improved.

Social network and mobile terminal technologies are platforms that allow consumers to easily post comments about product details (price, quality, logistics, and other product elements) or purchased services. Consumers rely on the comment section to obtain product information due to limited access to online products when shopping. Chevalier and Mayzlin (2006) proposed that the comments reflected more comprehensive and realistic information [1]. Furthermore, online reviews provide product 
information to consumers that can help verify the product information and promote purchase decisions. Forman et al. (2008) pointed out that online reviews had a significant impact on product sales [2]. With the in-depth analyses of these comments, companies can accurately understand the consumer's focus regarding various products or services. John and Suzan (2006) found that online reviews of consumers in China and the United States were influenced by differences in personal cultural background, online shopping confidence, and consumer market characteristics. Online reviews have a greater impact on Chinese consumers than on American consumers, and China's online consumer market is large [3]. Therefore, researching the impact of Chinese consumer online reviews on enterprise product sales can be theoretically and practically significant. Sebastiani (2002) pointed out that the analysis and process of manual or traditional commenting not only consumed a good amount of labor and financial resources, but also had low efficiency and poor accuracy [4]. Today, deep learning has gained widespread attention as an emerging field of machine learning [5]. Deep networks built through deep learning have shown excellent performance in unsupervised feature extraction. The convolutional neural network $(\mathrm{CNN})$ is an effective autonomous learning feature in deep learning, extracts higher-level semantic features from raw data, and uses weight share to improve training accuracy (Krizhevsky et al. 2012) [6]. At present, the model has been successfully applied to image processing (Deng et al., 2009) [7], speech recognition (Ainath et al., 2015) [8], and other fields. The field of natural language processing (NLP) has also attracted the attention of many scholars with the advent of the big data era. Collobert and Weston (2008) solved NPL-related problems through CNNs. CNN models have been proven to achieve superior results in solving these kinds of problems [9]. Kim (2014) applied CNNs to text classification problems in multiple fields and achieved significant results, indicating superior text classification based on CNN performance [10]. Competitive pressures are increasing as the scale of the fresh product trade continues to grow and fresh e-commerce companies continue to emerge. The quality of fresh e-commerce logistics service restricts the sustainable development of enterprises due to the particularity of fresh products (i.e., finding the logistics service elements that consumers pay attention to). Improving logistics services pointedly is helpful for fresh e-commerce enterprises. The research achievements of text mining based on deep learning have been featured in the field of NLP. Thus, this study used the CNN model in deep learning to analyze online reviews of fresh e-commerce logistics services and therefore understand consumers' shopping experiences with regard to the logistics service quality of fresh e-commerce enterprises. According to the problems of logistics service quality reflected by online reviews, fresh e-commerce enterprises formulate corresponding management measures to improve customer satisfaction. Consumer satisfaction is an important factor to promote the sale of fresh agricultural products and the sustainable development of commercial enterprises. Consumer satisfaction with logistics services of commercial enterprises determines whether the sale of fresh agricultural products on an e-commerce platform is sustainable. Therefore, focusing on the sustainable development of a fresh e-commerce platform and the sustainable sale of fresh agricultural products, this study conducted an in-depth learning of online reviews with text mining technology, hoping that this study can provide suggestions for fresh e-commerce enterprises to do a good job in logistics service quality management and enhance customer satisfaction.

\section{Literature Review}

Fresh e-commerce has been the focus of many scholars since 2012. Research on fresh e-commerce has focused on its development pattern, supply chain management strategy, and customer purchase behavior. Huang and Liu (2014) believe that the market demand for fresh e-commerce is large, but the problem of "last mile" distribution is difficult [11]. Thus, the development direction of combining localization with $\mathrm{O} 2 \mathrm{O}$ is insisted. Guritno et al. (2015) studied the influencing factors affecting the performance of the fresh product supply chain from the supply chain perspective and proposed different inventory management strategies for unique and common fresh products [12]. Maruyama et al. (2016) investigated the online shopping behavior for fresh food among residents of three cities in China and found that the freshness and availability of foods affected the consumers' willingness to purchase [13]. 
Fresh e-commerce enterprises need to continuously improve their logistics services to ensure the freshness of products and fast distribution to meet and improve customer satisfaction. Yeo (2018) believed that the $\mathrm{B} 2 \mathrm{C}$ trading of fresh produce is growing rapidly, thus becoming an important marketing and procurement channel [14]. Customers regard logistics service as an important factor for measuring the reliability of fresh e-commerce companies and proposing logistics services for the B2C trading of fresh products. The quality evaluation structure, using exploratory factor analysis, shows a direct correlation between the quality of logistics services and the success of e-commerce in the direct sales of fresh products. In-depth research has identified people as the main body to measure the quality of logistics services, and the research focus has gradually shifted from the perspective of providing services to purchasing or receiving services. Therefore, the measurement methods of logistics services have been widely studied. Perreaul and Russ (1974) put forward the 7Rs (Right Quality, Right Quantity, Right Price, Right Commodity, Right Time, Right Place, Right Customers) theory, the core of which is whether the enterprise can provide suitable products and services for their customers at the right time, the right place, the right way, and the right price to meet the individual needs of customers [15]. Mentzer et al. (1999), based on the SERVQUAL model in the research of logistics service quality combined with the characteristics of logistics service, proposed the Logistics Service Quality (LSQ) evaluation model (including nine indicators for measuring the quality of logistics services) [16]. The research pointed out that the impact of each index on different industries and on satisfaction varied. Pan and Nguyen (2015) used a balanced scorecard and a multi-criteria decision-making system to investigate key performance indicators to improve customer satisfaction in the service process and established four dimensions of a customer service capability evaluation model [17].

The quality of the logistics service plays a vital role in fresh e-commerce enterprises and is an important part of service quality. Many studies have shown that service quality is an important factor affecting customer satisfaction. Farooq et al. (2018) collected data from 460 respondents and assessed the impact of Malaysian Airlines' service quality on overall customer satisfaction based on a structural equation model. The results show that airlines should pay attention to all aspects of service quality, especially personnel service and image, to improve customer satisfaction [18]. Diallo et al. (2018) performed cross-cultural studies of the importance of mall service quality and satisfaction in Morocco, Senegal, and Tunisia (sampling 750 real customers), which indicated that the quality of service in a mall actively promotes customer satisfaction [19]. Therefore, the core task for fresh e-commerce enterprises is to improve their logistics service quality based on customer satisfaction. According to Oliver (1981), expectation-false evidence theory adopts the cumulative trading perspective [20]. Customer satisfaction refers to the evaluation of target products or services by customers based on a subjective comparison of the expected quality and perceived quality of the products or services. Customer satisfaction reflects not only the satisfaction degree of a customer with a product or service, but also the effect of the product or service provided by the enterprise to satisfy the customer demand (Ping, 2014) [21]. Fierce market competition has changed the competition between enterprises from product competition (the original state) to customer resources competition. Rabbani et al. (2018) aimed to gain a competitive advantage in the current business environment [22]. Thus, customer focus, researching customers, and exploring how to access customer resources have become indispensable elements of sustainable competitive advantage. The first condition for obtaining customer resources is customer satisfaction, because satisfaction can bring loyalty, and loyal customers are a stable source of profit for companies (Berry and Parasuraman, 1992) [23]. Westbrook and Oliver (1991) pointed out that customer loyalty can be increased by a positive correlation between customer satisfaction and profit levels, indicating future profit increases for companies [24]. Enterprises can recognize their standing in the market competition, identify the factors that lead to customer dissatisfaction, and implement countermeasures accordingly by comparing their level of customer satisfaction with those of the other enterprises in the industry. Presently, customer satisfaction research has mainly focused on the construction of customer satisfaction models. Vasic et al. (2019) studied the online shopping market in Serbia and defined a conceptual model with seven variables (security, information availability, 
transportation, quality, price, time, and customer satisfaction) and verified the validity of the model through confirmatory factor analysis and the partial least square method. The results obtained confirm that the customer satisfaction of the online shopping market in Serbia was directly dependent on the following factors: safety, availability of information, transportation, quality, price, and time [25]. Gao et al. (2006) developed a set of retail customer satisfaction measurement scales suitable for China where a random sample survey was conducted nationwide on 20 large-scale supermarket chains with the highest retail sales. The study identified good quality and low price as the factors that had the greatest impact on customer satisfaction, followed by the shopping experience. Meanwhile, in-store service and shopping convenience have no effect on customer satisfaction [26]. Ting (2018) reinterpreted previous research on satisfaction modeling and proposed the existence of nonlinear relationships to simulate two closely related but distinct countries: Malaysia (developing country) and Singapore (developed country). Online banking customers, using a systematic step-by-step hierarchical adjustment regression approach, attempted to understand the relationship between repurchase intentions, satisfaction, and trust after bank size adjustment. Malaysia and Singapore depicted linear and nonlinear relationships, respectively. The survey results show that modeling online banking customers through satisfaction was dependent on the country's economic development [27]. The customer satisfaction models mentioned in the above research were all established from the company or industry perspective. At present, the decisive factor for consumers of fresh goods in evaluating the quality of logistics services is whether expectations are met upon product receipt (timeliness of delivery, quality of the goods, freshness, and similar factors). This study aspired to address concerns regarding how fresh e-commerce enterprises can understand the needs of logistics service objects, improve the quality of logistics services according to the needs of consumers, and achieve certain customer satisfaction, which has become an important issue faced by fresh e-commerce.

\section{Methodology and Data}

\subsection{Proposed Methodology}

High-value information is hidden in online comment text data and has an important impact on the perception and purchase decision behavior of potential consumers and affects the sales volume of products from e-commerce platforms and manufacturing enterprises. Guen et al. (2018) clarified that consumers not only shared their product experiences through online reviews, but also reviewed products [28]. Online reviews affect product marketing, and companies use online reviews to understand the attitudes and perceptions of consumers of their products. However, these exist in the form of unstructured text data. Thus, online review text mining has gained the increased attention of scholars and has become a hot spot in research and enterprise practice. $\mathrm{CNN}$ is a kind of feedforward neural network that has local perception characteristics and weight sharing, which can greatly reduce the training parameters and thus accelerate the training speed (Lecun et al. 2015) [29]. In 2014, Kalchbrenner et al (2014) introduced a dynamic CNN method that could be used to model English sentences [30]. The feature vectors of the full text can be obtained by K-max pooling operation, which remove the dependence on the decision tree method and solve the problem of the difficulty and inaccuracy of manually selecting feature in traditional text classifiers and obtain better results of text categorization in the evaluation of English text categorization. Figure 1 presents the concrete structure. 


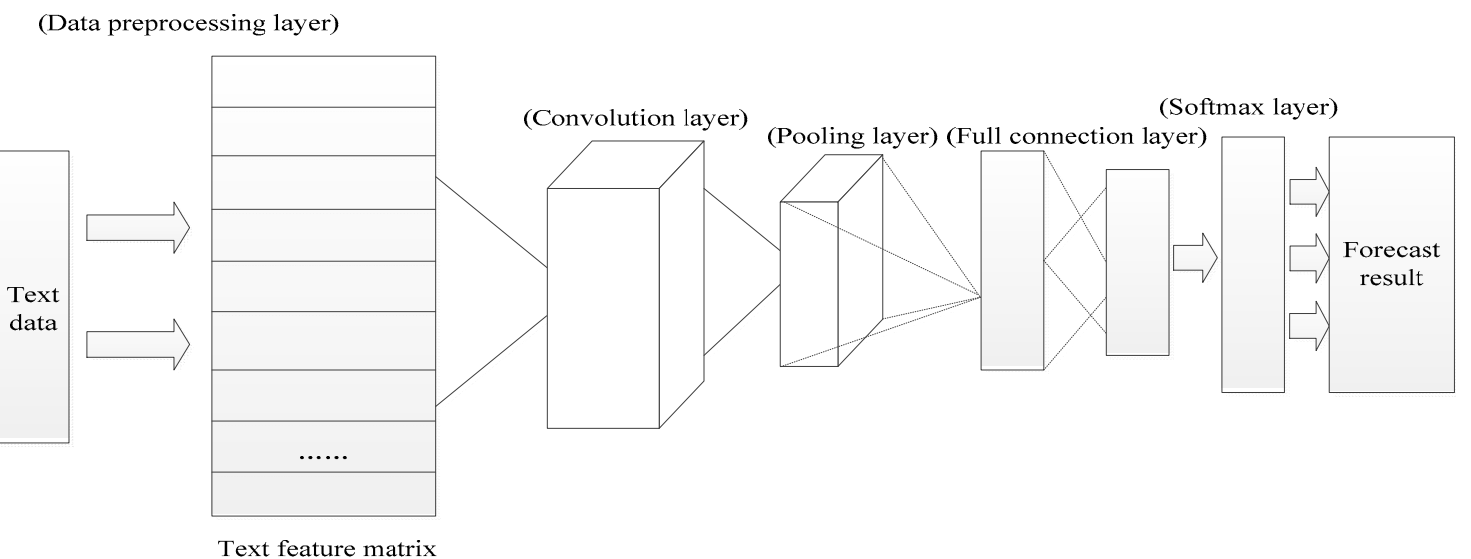

Figure 1. Text classifier structure based on Convolutional Neural Networks (CNN).

1. Data preprocessing layer: First, the comment content is partitioned and transformed into a sequence of words. Then, the word sequences are converted into sequences with word numbers (the words in each vocabulary are unique) as elements through the embedded layer (Collobert et al. 2011) [31]. Finally, each element (a word) in the word number sequence is expanded into a word vector in the form of a word vector where each piece of comment information is $x_{i}(i=1 \backslash 2 \backslash 3 \ldots)$. The matrix is represented by $n \times k$, where $n$ is the length of the word that constitutes the comment information, and $k$ represents the dimension of the word vector $\mathrm{x}_{\mathrm{i}}$.

2. Convolution layer: This layer is a feature extraction process. In the initial operation of the model, a convolution kernel with a reasonable size is set, and a feature matrix is obtained by extracting a feature from a convolution kernel. The different regions of the original text feature matrix are checked by the same convolution to transform the same information, generalize the local feature, and form a more abstract high-level feature matrix when extracting a particular kind of feature. The result is

$$
\mathrm{c} i=f(w \bullet x i: i+h-1+b)
$$

where $c_{i}$ represents the $i$ th eigenvalue corresponding to the convolution operation; $f(\cdot)$ indicates the choice of the layer's convolution kernel function; $w$ represents the weight matrix in the filter $\left(w \in \mathrm{R}^{\mathrm{h} * \mathrm{k}}\right.$, with $\mathrm{h} \times \mathrm{k}$ representing the size of the filter); $b$ indicates bias; and $x_{i: i+h-1}$ indicates the length of a word from the $i$ th word in the comment message to the $(i+h-1)$ th word. A more abstract high-level characteristic matrix $c$ is obtained after the convolution layer.

$$
c=[c 1, c 2, \ldots, c n-h+1]^{T}
$$

where $c \in R^{n-h+1}$.

3. Pool layer: The convolutional layer's characteristic matrix map can be aggregated using the method of maximum or average pool layer, which can greatly reduce the text's feature matrix. This process can reduce the number of parameters in the final full join layer. Not only can the speed of calculation be accelerated, but the problem of overfitting can also be effectively prevented. Different feature matrix graphs represent the features of different aspects of the text. Each characteristic matrix graph is pooled to obtain the overall features of the text and link them together. The overall features of the text can be expressed as

$$
\bar{c}=\max (c 1, c 2, \ldots, c n-h+1)
$$

4. Full connection layer: The original text information is abstracted into higher information content features after convolution layer and pool layer processing. These features are extracted and integrated in this layer to complete the classification task. Output $\mathrm{Y}$ is a $1 \mathrm{D}$ real vector represented as

$$
Y=[y 1, y 2, \ldots, y r]
$$


where $\mathrm{y}_{\mathrm{r}}$ is the rating of the comment information belonging to a certain category and $\mathrm{r}$ is the number of classification categories.

5. Softmax layer: Softmax is an output layer function in a neural network that calculates the value of the output layer. It is mainly used in the last layer of the neural network as the output layer for multi-classification. The probability of converting $\mathrm{Y}$ into a category through the softmax function of this layer is as follows: $[\mathrm{p}(\mathrm{y} 1), \mathrm{p}(\mathrm{y} 2), \ldots, \mathrm{p}(\mathrm{yr})], \mathrm{p}(\mathrm{yi})$, and the formula is

$$
p(y i)=\frac{e^{y i}}{\sum_{k} e^{y k}}
$$

Take $\max \left[\mathrm{p}\left(\mathrm{y}_{\mathrm{i}}\right)\right]$ as the category to which the comment information belongs.

Online comment text mining is the feature classification of text content. This study took the comments issued by customers after purchasing fresh products online as the research object and, through the processing of the $\mathrm{CNN}$ model, obtained the factors that influenced the customer satisfaction of fresh food e-commerce logistics service. Thereafter, the influence factors in each review were scored to determine the emotional tendency of each online review. Finally, correlation analysis was used to obtain the significance of the impact. This study presents an online review text mining process based on $\mathrm{CNN}$, as shown in Figure 2.

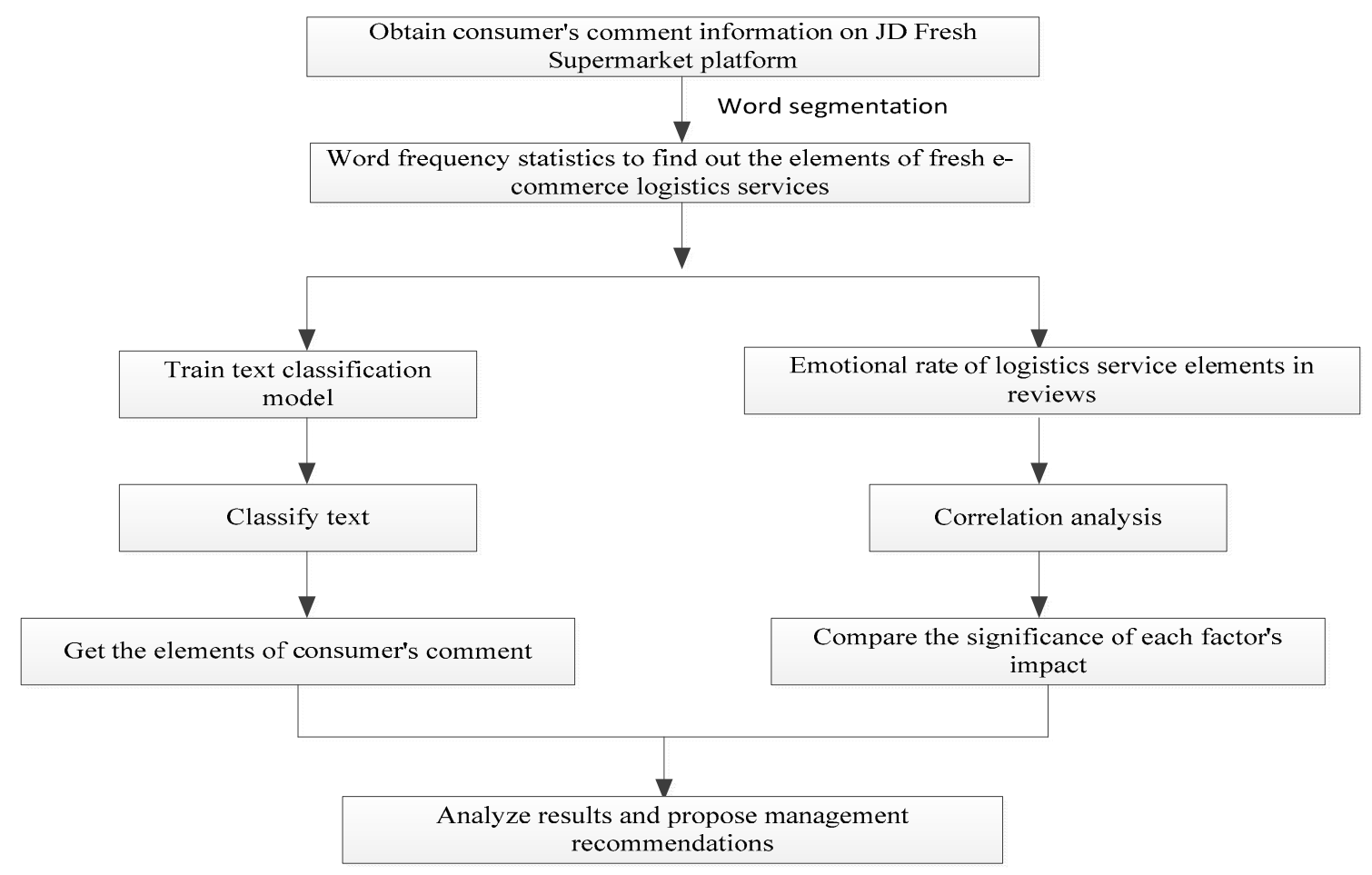

Figure 2. Online comment text mining process based on $\mathrm{CNN}$.

\subsection{Data Collection}

The Alibaba Group and JD, two giants of integrated e-commerce in China, take advantage of their brand advantages and occupy nearly half of the share of fresh e-commerce. The web crawler software Octopus was used in this study to collect the comments on logistics issued by the users who bought fruit from the JD Fresh Supermarket. A total of 15,000 related comments were collected and saved in text format. The Python programming language was used to deal with the word segmentation of the text. 


\subsection{Word frequency statistics}

The word frequency statistics website (http://corpus.zhonghuayuwen.org/) was used to calculate the word frequency of the comments processed by word segmentation. The words with frequencies greater than or equal to 10 were selected, and some meaningless phrases were removed. Table 1 presents the results.

Table 1. High-frequency words and the frequency statistics of online e-commerce reviews.

\begin{tabular}{cccccc}
\hline $\begin{array}{c}\text { High-frequency } \\
\text { Words }\end{array}$ & $\begin{array}{c}\text { Word } \\
\text { Frequency/Frequency }\end{array}$ & $\begin{array}{c}\text { High-frequency } \\
\text { Words }\end{array}$ & $\begin{array}{c}\text { Word } \\
\text { Frequency/Frequency }\end{array}$ & $\begin{array}{c}\text { High-frequency } \\
\text { Words }\end{array}$ & $\begin{array}{c}\text { Word } \\
\text { Frequency/Frequency }\end{array}$ \\
\hline Velocity & 880 & Quality & 241 & Rapid & 23 \\
Logistics & 674 & Attitude & 237 & Refund & 16 \\
Express & 649 & Strict & 84 & Speed & 16 \\
Quickly & 575 & Trust & 76 & Complete & 15 \\
Package & 527 & Description & 72 & Enthusiasm & 14 \\
Fresh & 424 & Quality & 63 & Guarantee & 13 \\
Door-to-door & 317 & Timely & 43 & Intimate & 12 \\
delivery & 302 & Responsible & 34 & Thoughtful & 11 \\
Service & 272 & Fast & 31 & Convenient & 10 \\
Convenience & 245 & Protection & 26 & Dispatching & 10 \\
Delivery & & & & \\
\hline
\end{tabular}

Table 1 shows that "speed", "express", and "logistics" imply that online shoppers paid more attention to the speed of the logistics distribution (i.e., "responsiveness"). "Package", "strict", and "complete" suggest that online shoppers focused on the packaging of goods in logistics services (i.e., "integrity"). "Description", "trust", and "security" indicate that online shoppers were more concerned with the consistency of the description of the merchant ("reliability"). "Delivery" and "convenience" indicate whether online shoppers received packages conveniently (i.e., "convenience"). "Service", "attitude", and "enthusiasm" show that online shoppers paid more attention to the service attitude of the customer service and delivery staff in the process of online shopping (i.e., "communication"). Word segmentation processing and word frequency statistical analysis concluded that the five elements of fresh e-commerce logistics service were "responsiveness", "integrity", "reliability", "convenience", and "communication". The quality of service was divided into subjective quality and objective quality. Objective quality is an objective indication of the performance and technical level of a product or service, and is the actual quality, whereas subjective quality covers the subjective response of the subject to the object, and is the quality of perception (Dodds W B and Monroe K B, 1985) [32]. Responsiveness, reliability, convenience, and communication are the subjective responses of customers in the process of logistics services that are the perceived quality (subjective quality), and the quality of "integrity" is the objective fact of commodity packaging in the logistics service process that is the actual quality (objective quality).

\subsection{Train Text Classification Model}

\subsubsection{Data Preparation}

The JD platform will simply classify the comments issued by consumers according to the above word frequency statistical analysis of the five elements of fresh e-commerce logistics services. With the use of the web crawler software Octopus, comments on these five elements published by customers who bought fruit from the JD Fresh Supermarket were gathered. Each element collected 10,000 and 50,000 comments. The training sample size was one of the most direct factors affecting the classification effect and was also the basis of the whole study. Therefore, ensuring the number of samples was necessary. Thereafter, the comments were partitioned, word vector coding was performed, and the text was converted into a calculation. The computer can recognize the vector matrix form as the input of the model. 


\subsubsection{Model parameter setting}

This study developed a CNN based on a Keras framework, and a five-class text classifier was obtained by training. The network parameters were often adjusted according to the amount of data, where $40 \%$ of the training set was randomly selected as the verification set, and the rest formed the real training set (i.e., the experiment of Turian (2010)) [33]. Table 2 shows the remaining parameter settings.

Table 2. CNN parameter settings.

\begin{tabular}{cc}
\hline Parameter & Parameter Values \\
\hline Convolution window size & $5 \times 50$ \\
Batch & 128 \\
Dropout & 0.3 \\
Learning rate & 0.01 \\
Iterations & 50 \\
\hline
\end{tabular}

The experiment results show that there were more complex results when using more parameters that improved the classification ability of the model. However, a layer of the convolution layer and a layer of the pool layer were used to train the model to reduce the optimization difficulties caused by the complexity of the model. Optimization methods of the neural network include batch gradient descent and stochastic gradient descent methods. The batch gradient descent method is the most primitive method. The main idea is that all samples are used to update each parameter, but the training process will be excessively slow when the sample size is large. The stochastic gradient descent method is the most commonly used optimization method at present. Its specific idea is to use a sample to update each parameter. Its training speed is very fast, and the momentum term can accelerate the optimization in the correlation direction and suppress the oscillation when the gradient changes direction. The weight parameter update formula is

$$
w k=w k-1-\eta k \frac{\partial}{\partial w k} J(w k)
$$

where $w$ is the weight parameter; $\eta$ is the learning rate; and $J(w k)$ is the error loss function. The gradient of the $J$ function was obtained by finding the partial derivative of the $J$ function, that is, the direction in which the $J$ function falls most quickly. The parameters were updated in this direction, so that the function value of $J$ becomes smaller and smaller. Therefore, this study used the SGD update rule to train the neural network by the random gradient descent method. Parameter settings $(\mathrm{lr}=0.01$, momentum $=0.9$, decay $=0.0$, nesterov $=$ false).

\section{Results}

\subsection{Experiment Results}

After 50 iterations, the accuracy of the test set was $81.25 \%$ (Shardlow et al. (2018)) [34]. It was noted that the $\mathrm{CNN}$ classification model based on deep learning is more effective than the traditional text mining method. The traditional text classification method is based on the word bag model (BOW), which only contains word frequency information and ignores the context of the sentence. However, the CNN model can make up the deficiency of traditional text classification.

\subsection{Data Processing}

Among the fresh fruits, apples occupied $65.99 \%$ of the total sales of fruits, which accounted for $24.53 \%$ of the total transactions (Liang et al. 2012) [35]. The ratio of the number of favorable comments to the number of bad comments was controlled to 3:1 because the number of favorable comments posted by consumers regarding buying fruit at JD Fresh was considerably greater than the number of negative comments (data source: https://item.jd.com/3756271.html\#comment). In line with the actual 
situation, this study carried out classification and prediction. With the amount of data used for the positive feedback of 1500 articles, 500 were identified as poor evaluation. The trained models were derived after preprocessing the collected data, and Table 3 shows the classification results.

Table 3. Results of text categorization (partial).

\begin{tabular}{ccccccc}
\hline $\begin{array}{c}\text { Order } \\
\text { Number }\end{array}$ & Convenience & Communication & Reliability & Integrity & Responsiveness & Category \\
\hline 1 & 0.277 & 0.212 & 0.042 & 0.358 & 0.111 & Integrity \\
5 & 0.333 & 0.311 & 0.354 & 0.001 & 0.001 & Reliability \\
8 & 0.003 & 0.299 & 0.275 & 0.188 & 0.235 & Communication \\
325 & 0.003 & 0.039 & 0.001 & 0.001 & 0.956 & Responsiveness \\
393 & 0.004 & 0.588 & 0.406 & 0.001 & 0.001 & Communication \\
411 & 0.117 & 0.058 & 0.203 & 0.269 & 0.353 & Responsiveness \\
839 & 0.001 & 0.001 & 0.996 & 0.001 & 0.001 & Reliability \\
920 & 0.074 & 0.443 & 0.481 & 0.001 & 0.001 & Reliability \\
938 & 0.013 & 0.003 & 0.973 & 0.001 & 0.010 & Reliability \\
1481 & 0.042 & 0.063 & 0.163 & 0.448 & 0.284 & Integrity \\
1530 & 0.010 & 0.985 & 0.003 & 0.001 & 0.001 & Communication \\
1848 & 0.004 & 0.393 & 0.600 & 0.001 & 0.002 & Reliability \\
1970 & 0.001 & 0.393 & 0.001 & 0.605 & 0.001 & Integrity \\
\hline
\end{tabular}

After classification of the 2000 reviews on logistics, 199 were concerned with the responsiveness of logistics services, 337 regarded the convenience of logistics services, and 340 were particularly about the completeness of the logistics services. A total of 357 customer comments focused on the communication of the logistics service, and 767 were concerned about the reliability. Figure 3 presents the factors that affect customer satisfaction.

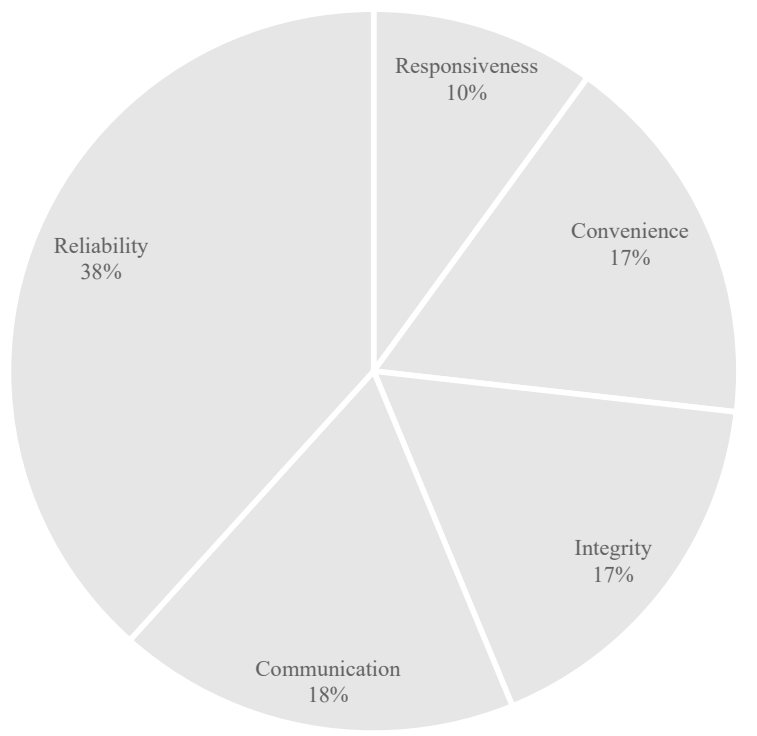

Figure 3. Proportion of factors affecting customer satisfaction.

Of the 1500 favorable reviews on logistics, 108 were concerned with the responsiveness of the logistics services, 159 were on communication, and 295 on integrity. A total of 309 customer comments were on the convenience of the logistics services, and 629 about reliability. Figure 4 presents the proportion of favorable factors. 


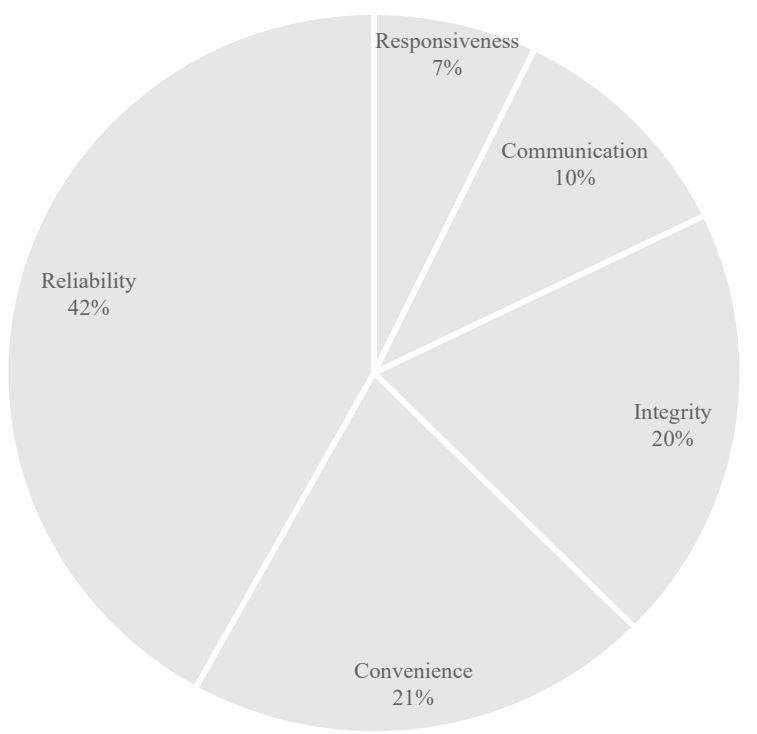

Figure 4. Proportion of factors with favorable comments.

Of the 500 poor comments on logistics, 28 were concerned with the convenience of the logistics services, 45 about integrity, and 91 about responsiveness. A total of 138 customer reviews were concerned about the reliability of the logistics services and 198 about communication. The proportions of the different factors are shown in Figure 5.

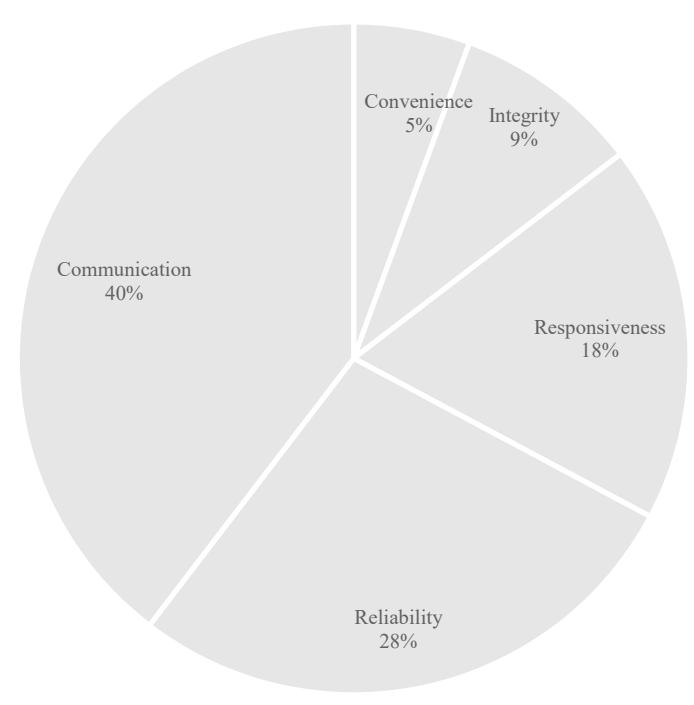

Figure 5. Proportion of factors in poor comment.

An analysis of the above customer comment data suggests that (of the 2000 comments) customers were most concerned with the reliability of the logistics services. Among them, customers paid more attention of the reliability of logistics services in praise when leaving positive feedback, while customers paid more attention to the communication of logistics services during a poor evaluation. The customer's attitude to relevant logistics service factors will affect their satisfaction. This study used emotional analysis to study a customer's attitude toward logistics service elements and further discussed the impact of logistics service elements on customer satisfaction. 


\subsection{Sentiment Analysis}

\subsubsection{Extraction of Feature Words}

Sentiment analysis (also known as opinion mining) is the process of analyzing, processing, inducing, and reasoning the subjective text with emotional color by using text mining technology to analyze a substantial number of unstructured comment texts. Emotional analysis of online reviews begins by with extracting text feature words from comments. Li, F. et al. (2010) used syntactic structure tree Skip-Tree CRFs to extract evaluation feature words for affective polarity analysis [36]. Li, C.W. et al. (2016) used the inverse text frequency index (IDF) method, which is commonly used in information science to sort keyword weights, extract important feature words, and carry out affective analysis [37]. The above method is efficient, but ignores the error caused by the synonym of the feature words in the comment text, thus affecting the accuracy of the research results. Therefore, this study adopted a semiautomatic way to set the synonym table of feature words to improve accuracy. The specific method classifies the characteristic words and their synonyms in the five logistics service factors that affect customer satisfaction and forms a synonym table of feature words, as shown in Table 4 .

Table 4. Synonym list of feature words (partial).

\begin{tabular}{ccccc}
\hline Responsiveness & Communication & Convenience & Integrity & Reliability \\
\hline Velocity & Service & Convenient & Package & Reliable \\
Logistics & Attitude & Facilitate & Intact & Description \\
Express & After-sale serve & Door-to-door delivery & Complete & Expected value \\
Deliver & Refund & Direct & Package box & Trust \\
Dispatch & Express courier & Labor save & In good condition & Safeguard \\
\hline
\end{tabular}

\subsubsection{Quantitative Score}

The study set a certain rate standard for the five influencing factors of logistics service to quantify the customer's comments on the five factors of logistics service. The grading rules for each factor were set according to the modifiers and characteristics of each influencing factor in the comment message, as shown in Table 5.

Table 5. Influence factor scoring rules.

\begin{tabular}{|c|c|c|c|c|c|}
\hline $\begin{array}{l}\text { Influence } \\
\text { Factors }\end{array}$ & 5 Score & 4 Score & 3 Score & 2 Score & 1 Score \\
\hline Responsiveness & Very fast & Fast & General/Normal & A little slow & Very slow \\
\hline Convenience & Very convenient & Door-to-door delivery & Not bad/General & $\begin{array}{l}\text { Not very } \\
\text { convenient }\end{array}$ & Trouble/Inconvenient \\
\hline Integrity & $\begin{array}{l}\text { The packaging is } \\
\text { very careful }\end{array}$ & Intact/ Undamaged & General/Normal & $\begin{array}{c}\text { Poor packing/ } \\
\text { damaged }\end{array}$ & Very poor package \\
\hline Reliability & $\begin{array}{l}\text { Very consistent } \\
\text { with the } \\
\text { description }\end{array}$ & Tally & Acceptable & $\begin{array}{l}\text { A little different } \\
\text { from the } \\
\text { description }\end{array}$ & $\begin{array}{l}\text { Completely } \\
\text { inconsistent }\end{array}$ \\
\hline
\end{tabular}

Each factor was quantified in the comment information according to the grading rules of each influence factor. In the process of grading strictly by the scoring rules, the customer's comments on the factors not involved in the information defaulted to three points, that is, the recognition of them. Comments such as "in short, all 5 points good", and "overall feeling average" meant that the summation statement was mainly based on the summary information to score. The same semantic flexibility could also be performed according to the intensity of the emotional color ("in time" can be equated with "fast"). The scores of the factors that affected customer satisfaction were obtained after counting the scores of each comment information as shown in Table 6. The comment information was transformed into digital information through emotional quantification to determine the overall comment data of customers on JD Fresh e-commerce logistics services. 
Table 6. Score of customer satisfaction influential factors (partial).

\begin{tabular}{cccccc}
\hline Order Number & Responsiveness & Communication & Convenience & Integrity & Reliability \\
\hline 1 & 5 & 4 & 4 & 4 & 4 \\
28 & 5 & 3 & 3 & 3 & 5 \\
109 & 4 & 5 & 5 & 3 & 4 \\
183 & 3 & 3 & 4 & 3 & 4 \\
1012 & 4 & 4 & 3 & 4 & 4 \\
\hline
\end{tabular}

\subsubsection{Correlation Analysis}

SPSS statistical software was used to analyze the correlation between customer satisfaction and the influencing factors of fresh e-commerce logistics service. We imported the score information table for the above 2000 comments into the software. Table 7 presents the results of the regression analysis, taking customer satisfaction as the dependent variable y (bad evaluation value 1 , favorable evaluation value 2 ) and the five influencing factors obtained from the above analysis as the independent variables (convenience $X_{1}$, communication $X_{2}$, reliability $X_{3}$, integrity $X_{4}$, and responsiveness $X_{5}$ ).

Table 7. Correlation coefficients.

\begin{tabular}{|c|c|c|c|c|c|c|c|c|}
\hline \multirow{2}{*}{\multicolumn{2}{|c|}{ Model }} & \multicolumn{2}{|c|}{$\begin{array}{c}\text { Non-standardized } \\
\text { Coefficient }\end{array}$} & \multirow[t]{2}{*}{$\begin{array}{l}\text { Standard } \\
\text { Coefficient }\end{array}$} & \multirow{2}{*}{\multicolumn{2}{|c|}{ t Sig. }} & \multicolumn{2}{|c|}{ Collinear Statistics } \\
\hline & & B & $\begin{array}{l}\text { Standard } \\
\text { Error }\end{array}$ & & & & Tolerance & VIF \\
\hline \multirow[t]{6}{*}{1} & Variable & 0.424 & 0.025 & & 16.714 & 0.000 & & \\
\hline & $X_{1}$ & 0.107 & 0.006 & 0.229 & 16.864 & 0.000 & 0.931 & 1.074 \\
\hline & $X_{2}$ & 0.086 & 0.005 & 0.243 & 17.232 & 0.000 & 0.864 & 1.158 \\
\hline & $X_{3}$ & 0.101 & 0.006 & 0.272 & 16.869 & 0.000 & 0.658 & 1.519 \\
\hline & $X_{4}$ & -0.003 & 0.006 & 0.007 & -0.505 & 0.614 & 0.852 & 1.173 \\
\hline & $X_{5}$ & 0.172 & 0.005 & 0.517 & 33.739 & 0.000 & 0.730 & 1.370 \\
\hline
\end{tabular}

Table 7 shows that variables $X_{1}, X_{2}, X_{3}$, and $X_{5}$ passed the significance test. The test of significance of less than 0.05 also showed that convenience, communication, reliability, and responsiveness in the logistics service of fresh food e-commerce had a significant impact on customer satisfaction. The normalization coefficient represents that, in the regression equation, a greater degree of explanation of each variable to the dependent variable means a greater normalization coefficient. The influence of the variable is stronger, and the responsiveness factor of the logistics service has the most influence on customer satisfaction. The responsive factor of the logistics service has the strongest influence on customer satisfaction, while the convenience factor has the weakest.

\section{Discussion and Conclusions}

\subsection{Discussion}

This study used the CNN deep learning model and sentiment analysis method to analyze the comments published by customers after purchasing fresh products online and explore the logistics service factors and their impact on customer satisfaction. The reliability of logistics service from the data of the classification results accounted for $38 \%$ of the 2000 comments, $18 \%$ of the communication factors, and $17 \%$ of the convenience and integrity factors. The responsiveness factors accounted for $10 \%$, indicating that the majority of customers paid attention to the reliability of logistics service when shopping for fresh goods online, that is, the reliability of the business service (whether the goods are delivered on time, with accuracy, committed level of fulfillment, etc.) and the proportion of customers who paid attention to the communication, convenience, and integrity of the logistics services was comparable, while very few customers paid attention to the responsiveness of logistics services. The regression analysis results suggest that the convenience, serviceability, reliability, and 
responsiveness of the fresh e-commerce logistics service had a significant positive impact on customer satisfaction, whereas the impact of integrity on customer satisfaction was not significant. This result is consistent with the studies by Ha (2018) [38] and Park (2002) [39], indicating that the subjective logistics service quality of customers in the process of purchasing fresh produce online had an important impact on their satisfaction. In addition, this study found that the impact of integrity on customer satisfaction was not significant. This result is consistent with Wang's claim that the objective logistics service quality has no significant impact on customer satisfaction (Wang, 2006) [40]. Therefore, the main factor affecting customer satisfaction is the quality of service that customers experience during the online shopping process. In summary, the results show that the reliability of logistics services (38\%) that customers focused on had an impact on customer satisfaction of only 0.272 , the communication of logistics services $(18 \%)$ that customers focused on had an impact on customer satisfaction of only 0.243 , the convenience of logistics services $(17 \%)$ that customers focused on had an impact on customer satisfaction of only 0.229 , while the responsiveness $(10 \%)$, which customers paid the lowest attention to, had the maximum impact on customer satisfaction of 0.517 and which the integrity of logistics services $(17 \%)$ that customers focused on had no significant impact on customer satisfaction. The responsiveness of logistics service has the greatest impact on customer satisfaction because, nowadays, with online shopping being generally accepted by consumers and has even become the main way of daily shopping, people not only pay attention to whether the merchants deal with orders on time and whether they deliver packages on time, but also pay more attention to when customers put forward the idea of returning goods and if the merchant can contact the customers in a timely manner and provide them with satisfactory solutions to minimize the loss of customers and improve customer satisfaction.

On the one hand, logistics service, as an important link and basic guarantee in the process of online shopping transactions, can enhance the loyalty of customers to enterprises. E-commerce companies must enhance the repeat purchase intention of customers by improving the quality of logistics services and obtain a stable customer base. Only a stable customer base can maintain the competitive advantage of e-commerce companies. Meanwhile, e-commerce companies can improve their own logistics systems based on the research results of this study by identifying the inadequacies and formulating corresponding optimization measures to enable enterprises to achieve longer-term development. From the perspective of responsiveness, e-commerce enterprises need to configure special personnel to process customer orders in time, and inform customers in a timely manner to verify the order information, thus confirming that there are no errors in the information; moreover, when customers inquire about products or logistics information during working hours, staff should reply in time and give detailed answers. Finally, if such customers are not satisfied with the products or services of the merchants, compensation measures should be put forward in time to reduce customer losses. From the point of view of reliability, e-commerce enterprises should keep their promises, deliver the package to the right place and give it to the right person within the prescribed time, and ensure that the products received by customers are consistent with the description by the merchants on the Internet. From the perspective of communication, e-commerce enterprises should provide professional training to their employees, improve their language expression ability and professional quality, maintain a positive and enthusiastic attitude in the process of communicating with customers, and, when facing questions posed by customers, service personnel should answer patiently and provide customers with the most valuable information. From the perspective of convenience, when customers buy goods online, e-commerce enterprises should ensure that access to the web page is convenient and the payment operation is easy; when customers receive express delivery, e-commerce enterprises should provide door-to-door delivery services to save time for their customers.

\subsection{Conclusions}

A text classification method based on a CNN model was proposed in this study to address the problems of not fully utilizing text context for traditional text categorization methods, relying on the manual extraction of features and rules, sparse representation of data, etc. The self-learning 
characteristics of CNNs were used to train word vectors, which avoided data sparsity. Classification tasks can be achieved using the convolutional layer to extract local features, the pooling layer to filter features, and setting up a fully connected layer to further abstract features. The experimental results confirm that convenience, communication, reliability, and responsiveness had a significant impact on customer satisfaction, whereas integrity had none. Therefore, it further proves the feasibility and effectiveness of the proposed method to better analyze the tendency of text information.

\subsection{Limitations and Future Research Trends}

Although some conclusions have been drawn through the use of in-depth learning in text mining technology, there are still many research deficiencies and limitations. For example, the data sources of this study were mainly fresh fruits, and not all comments on fresh agricultural products were grasped and analyzed, which may lead to a lack of representativeness regarding the research results. In the follow-up study, online comments on all kinds of fresh agricultural products will be taken as the research object to improve the universality of the experimental results. Based on the literature collation and the practical basis, this research divided the logistics service quality into five dimensions according to the operation process of the fresh e-commerce industry and logistics service. In the follow-up study, we will proceed from other angles and combine other attributes of the logistics industry to carry out different dimensions of the fresh e-commerce logistics service quality. In this study, when compiling the text classification model of a convolution neural network, only one layer of convolution layer and one layer of pooling layer were used for training. As the accuracy of the model training has not reached a particularly ideal state, the next step is to set up a multi-layer convolution layer in the model to improve the accuracy of the training.

Author Contributions: W.H. and C.Z. designed and wrote this article; L.W. and X.P. provided suggestions for this article.

Funding: This work was supported by the National Natural Science Foundation of China (Project Approval No. 71303094), the Major Project of the National Social Science Fund of China (Project Approval No. 14ZDA069), the Fundamental Research Funds for the Central Universities (Project Approval No. JUSRP51641A), and the National Natural Science Foundation of China (Project Approval No. 71871105).

Conflicts of Interest: The authors declare no conflict of interest.

\section{References}

1. Chevalier, J.A.; Mayzlin, D. The Effect of Word of Mouth on Sales: Online Book Reviews. J. Mark. Res. 2006, 43, 345-354. [CrossRef]

2. Forman, C.; Ghose, A.; Ghose, A.; Wiesenfeld, B. Examining the Relationship between Reviews and Sales: The Role of Reviewer Identity Disclosure in Electronic Markets. Inf. Syst. Res. 2008, 19, 291-313. [CrossRef]

3. Fong, J.; Burton, S. Electronic Word of Mouth: A Comparison of Stated and Revealed Behavior on Electronic Discussion Boards. J. Interact. Advert. 2006, 6, 61-70. [CrossRef]

4. Sebastiani, F. Machine learning in automated text categorization. ACM Comput. Surv. 2002, 34, 1-47. [CrossRef]

5. Hinton, G.E.; Salakhutdinow, R.R. Reducing the dimensionality of data with neural networks. Science 2006, 313, 504-507. [CrossRef]

6. Krizhevsky, A.; Sutskever; Hinton, G. Imagenet classification with deep convolutional neural networks. In Advances in Neural Information Processing Systems; MIT Press: Cambridge, MA, USA, 2012; pp. 1097-1105.

7. Deng, J.; Dong, W.; Socher, R. ImageNet: A large-scale hierarchical image database. In Proceedings of the 2009 IEEE Conference on Computer Vision and Pattem Recognition, Miami, FL, USA, 20-25 June 2009.

8. Sainath, T.N.; Kingsbury, B.; Saon, G.; Soltau, H.; Mohamed, A.R.; Dahl, G.; Ramabhadran, B. Deep convolutional neural networks for large scale speech tasks. Neural Netw. 2015, 64, 39-48. [CrossRef] [PubMed]

9. Collobert, R.; Weston, J. A unified architecture for natural language processing: Deep neural networks with multitask learning. In Proceedings of the 25th International Conference on Machine Learning, Helsinki, Finland, 5-9 July 2008; pp. 160-167. 
10. Kim, Y. Convolutional neural networks for sentence classification. In Proceedings of Empirical Methods in Natural Language Processing; ACL: New York, NY, USA, 2014; p. 1746.

11. Huang, L.; Liu, P. Key Technologies and Alogrithms' Application in Agricultural Food Supply Chain Tracking System in E-commerce. Comput. Comput. Technol. Agric. 2014, 420, 269-281.

12. Guritno, A.D.; Fujianti, R.; Kusumasari, D. Assessment of the Supply Chain Factors and Classification of Inventory Management in Suppliers' Level of Fresh Vegetable. Agric. Agric. Sci. Procedia 2015, 3, 51-55. [CrossRef]

13. Maruyama, M.; Wu, L.; Huang, L. The modernization of fresh food retailing in China: The role of consumers. J. Retail. Consum. Serv. 2016, 30, 33-39. [CrossRef]

14. Yeo, G. A Study on Extracting Factors of Logistics Service Quality of B2C Transactions in Agricultural Products. J. Shipp. Logist. 2018, 34, 355-376.

15. Perreault, W.D.; Russ, F. Physical Distribution Service: A Neglected Aspect of Marketing Management. MSU Bus. Top. 1974, 22, 37-45.

16. Mentzer, J.T.; Flint, D.J.; Kent, J.L. Developing a logistics service quality scale. J. Bus. 1999, 20, 9-32.

17. Pan, J.N.; Nguyen, H.T.N. Achieving Customer Satisfaction through Product service Systems. European J. Oper. Res. 2015, 247, 179-190. [CrossRef]

18. Farooq, M.S.; Salam, M.; ur Rehman, S.; Fayolle, A.; Jaafar, N.; Ayupp, K. Impact of Support from Social Network on Entrepreneurial Intention of Fresh Business Graduates: A Structural Equation Modeling Approach. J. Air Transp. Manag. 2018, 67, 169-180. [CrossRef]

19. Diallo, M.F.; Diop-Sall, F.; Djelassi, S.; Godefroit-Winkel, D. How Shopping Mall Service Quality Affects Customer Loyalty Across Developing Countries: The Moderation of the Cultural Context. J. Int. Mark. 2018, 26, 69-84. [CrossRef]

20. Oliver, R.L. Measurement and Evaluation of Satisfaction Processes in Retail Settings. J. Retail. 1981, 57, $25-48$.

21. Ping, H. Research on the Factors Affecting Customer Satisfaction of Logistics Service in B2C Network Shopping. J. He Fei Univ. Technol. (Soc. Sci. Ed.) 2014, 28, 31-38.

22. Rabbani, M.; Heidari, R.; Farrokhi-Asl, H. A bi-objective mixed-model assembly line sequencing problem considering customer satisfaction and customer buying behaviour. Eng. Optim. 2018, 50, 2123-2142. [CrossRef]

23. Berry, L.L.; Parasuraman, A. Marketing Services: Competing through Quality; The Free Press: New York, NY, USA, 1992; Volume 56, pp. 123-125.

24. Westbrook, R.A.; Oliver, R.L. The dimensionality of consumption emotion patterns and consumer satisfaction. J. Consum. Res. 1991, 18, 84-91. [CrossRef]

25. Vasic, N.; Kilibarda, M.; Kaurin, T. The Influence of Online Shopping Determinants on Customer Satisfaction in the Serbian Market. J. Theor. Appl. Electron. Commer. Res. 2019, 14, 70-89. [CrossRef]

26. Gao, W.; Fei, L.; Qibin, L. Empirical Research on Customer Satisfaction of Large scale Chain Supermarkets in China-Based on National Survey Data of 20 Large scale Chain Supermarkets. Manag. World 2006, 6, 101-110.

27. Ting, D.H. Modeling the customer satisfaction function: A two-country comparison. Electron. Mark. 2018, 28, 163-175. [CrossRef]

28. Guen, K.S.; Juyoung, K. Analyzing the discriminative attributes of products using text mining focused on cosmetic reviews. Inf. Process. Manag. 2018, 54, 938-957.

29. Lecun, Y.; Bengio, Y.; Hinton, G. Deep learning. Nature 2015, 521, 436-444. [CrossRef] [PubMed]

30. Kalchbrenner, N.; Grefenstette, E.; Blunsom, P. A Convolutional Neural Network for Modelling Sentences. arXiv 2014, arXiv:1404.2188.

31. Collobert, R.; Weston, J.; Bottou, L.; Karlen, M.; Kavukcuoglu, K.; Kuksa, P. Natural language processing (almost) from scratch. J. Mach. Learn. Res. 2011, 12, 2493-2537.

32. Dodds, W.B.; Monroe, K.B. The Effect of Brand and Price Information on Subjective Product Evaluations. Adv. Consum. Res. 1985, 12, 85-90.

33. Turian, J.; Ratinov, L.; Bengio, Y. Word representations: A simple andgeneral method for semi-supervised learning. In Proceedings of the 48th Annual Meeting of the Association for Computational Linguistics, Uppsala, Sweden, 11-16 July 2010; Association for Computational Linguistics: Stroudsburg, NY, USA, 2010; pp. 384-394. 
34. Shardlow, M.; Ju, M.; Li, M.; O’Reilly, C.; Iavarone, E.; McNaught, J.; Ananiadou, S. A Text Mining Pipeline Using Active and Deep Learning Aimed at Curating Information in Computational Neuroscience. Neuroinformatics 2018, 1-16. [CrossRef] [PubMed]

35. Liang, W.Z.; Yun, X.; Ge, R. Analysis of the characteristics of online shopping products in China. Agric. Econ. Issues 2012, 33, 40-43.

36. Li, F.; Han, C.; Huang, M.; Zhu, X.; Xia, Y.J.; Zhang, S.; Yu, H. Structure aware Review Mining and Summarization. In Proceedings of the International Conference on Computational Linguistics, Beijing, China, 23-27 August 2010; pp. 653-661.

37. Li, C.W.; Chuang, H.C.; Li, S.T. Hedonic Analysis for Consumer Electronics Using Online Product Reviews. In Proceedings of the IIAI International Congress on Advanced Applied Informatics, Kumamoto, Japan, 10-14 July 2016; pp. 609-614.

38. Ha, M. The Impact of the Port Logistics Service Quality on Customer Satisfaction and Loyalty. Korea Int. Commer. Rev. 2018, 33, 171-191.

39. Park, K. Logistics Service Quality and Customer Satisfaction in E-commerce. Asia Pac. J. Inf. Syst. 2002, 12, 237-253.

40. Kim, B.I. The Relative Effects of Three Dimensions of Port Logistics Service Quality on Customer Satisfaction. J. Korea Port Econ. Assoc. 2006, 22, 125-149.

(C) 2019 by the authors. Licensee MDPI, Basel, Switzerland. This article is an open access article distributed under the terms and conditions of the Creative Commons Attribution (CC BY) license (http://creativecommons.org/licenses/by/4.0/). 